\title{
Syndrome of normal pressure hydrocephalus: possible relation to hypertensive and arteriosclerotic vasculopathy $^{1}$
}

\author{
A. KOTO ${ }^{2}$, G. ROSENBERG ${ }^{3}$, L. H. ZINGESSER, D. HOROUPIAN, AND \\ R. KATZMAN \\ From the Departments of Pathology (Neuropathology), Radiology, and the Saul R. Korey Department of \\ Neurology, Albert Einstein College of Medicine, Bronx, New York, USA
}

SUMMARY A patient with clinical features of idiopathic normal pressure hydrocephalus, who responded dramatically to shunting, was found at necropsy to have a severe hypertensive and arteriosclerotic vasculopathy with multiple lacunar infarcts. There was no pathological evidence of thickened leptomeninges, fibrosis of the arachnoid villi, or Alzheimer's disease. An abnormal absorption mechanism was demonstrated with cisternography and by an increase in the concentration of homovanillic acid in the cerebrospinal fluid. It is suggested that vascular changes may play an important role in the pathophysiology in some cases of normal pressure hydrocephalus.

Since the introduction of the concept of normal pressure hydrocephalus by Hakim and Adams (1965) and Adams and associates (1965) as a potentially reversible form of dementia, the clinical symptomatology, diagnostic criteria, and results of shunting of cerebrospinal fluid have been well documented (Ojemann et al., 1969; Benson et al., 1970; Heinz ct al., 1970; Coblentz et al., 1973; Sypert et al., 1973; Messert and Wannamaker, 1974; Stein and Langfitt, 1974; Wood et al., 1974; Shenkin et al., 1975; Belloni et al., 1976; Jacobs et al., 1976; Katzman, 1977). In the patients who have come to necropsy, however, the pathology has been variable. Meningeal fibrosis with or without changes in the arachnoid granulations was the most common finding (Heinz et al., 1970; DeLand et al., 1972; Sypert et al., 1973, and Vessal et al., 1974), although some had pathological changes consistent with Alzheimer's disease (Coblentz et al., 1973; Schn et al., 1973; Stein and Langfitt, 1974). Several patients, however, did not show these changes, but instead demonstrated either amyloid angiopathy (Torack, 1975) or microvascular changes of hypertension with lacunar

\footnotetext{
${ }^{1}$ Work supported in part by N.I.H. grants NS 05275, and NS 03356. ${ }^{2}$ Address for reprint requests: Dr Atsuo Koto, Department of Pathology (Neuropathology), Albert Einstein College of Medicine, 1300 Morris Park Avenue, Bronx, N.Y. 10461, USA.

${ }^{3}$ Present address: Department of Neurology, University of New Mexico School of Medicine, Albuquerque, New Mexico, USA.

Accepted 20 September 1976
}

infarcts (Earnest et al., 1974). The present case report describes a patient with the clinical syndrome of normal pressure hydrocephalus who improved dramatically after a ventriculopleural shunt was inserted, but whose brain showed severe hypertensive and arteriosclerotic cerebrovascular disease together with an advanced lacunar state. We suggest that vascular changes can be a significant factor in the pathogenesis of some forms of normal pressure hydrocephalus.

\section{Case report}

The patient was a 67 year old, hypertensive man with a one year history of gait difficulty, urinary incontinence, and mild dementia. His hypertension was of long standing and had been treated with various medications. He also had a long history of alcohol abuse, but worked steadily as a shipping clerk until he retired at the age of 65 years. He was well until March 1974, when he first noticed shuffling of his gait which increased after walking a short distance. He also realised that his handwriting had become smaller and shakier, and he had difficulty in getting up from a sitting position. Neurological evaluation in June 1974 at another institution revealed normal mentation, snout and suck reflexes, paratonia in the upper extremities, and questionable spasticity and extensor plantar response in the left leg. L-dopa was prescribed because 
of the suspicion of Parkinson's disease, and a slight improvement in his gait was obtained. Laboratory studies, including measurements of serum vitamin $B_{12}$ level and thyroid function tests, were normal. Computerised transaxial tomography done at that time revealed marked ventricular enlargement without cortical atrophy. The gait disturbance was gradually progressive, and he had occasional urinary incontinence. However, according to his family, he remained mentally alert during this period. He was admitted to the neurology service at the Bronx Municipal Hospital Center in October 1974.

Past medical history except as noted above and family history were unremarkable.

On admission general physical examination was normal except for a blood pressure of 175/100 $\mathrm{mmHg}$. He was alert and oriented, but slow in speech and hesitant in answering questions. Although the examining physicians were not certain whether there was evidence of dementia, psychometric examination revealed a marked discrepancy between verbal IQ (118) and performance IQ (77) due in part to difficulty with timed tests (digit symbol, block design, and object assembly). The Mattis Dementia Rating Score (Coblentz et al., 1973) was 111 (normal 140-144) and moderate impairment of verbal learning was observed. He had a snout reflex. The gait was slow and unsteady with a wide base. At times he was totally unable to initiate walking as if his feet were stuck to the floor. The reflexes were hyperactive symmetrically, and there was a tonic foot grasp bilaterally. The muscle tone was mildly increased with some cog-wheel type rigidity of the neck and elbows. Muscle strength was normal as were sensation and cerebellar function.

Routine laboratory tests were all normal. A lumbar puncture showed an opening pressure of $122 \mathrm{mmH}_{2} \mathrm{O}$. The cerebrospinal fluid (CSF) protein was $0.72 \mathrm{~g} / \mathrm{l}$ and the glucose was $5.6 \mathrm{mmol} / 1$; there were no cells. Homovanillic acid (HVA) level of the CSF was $132 \mu \mathrm{g} / \mathrm{l}$ (normal $50 \pm 15 \mu \mathrm{g} / \mathrm{l}$ ), and the 5-hydroxyindoleacetic acid (5-HIAA) level was 53 $\mu \mathrm{g} / \mathrm{l}$ (normal $30 \pm 10 \mu \mathrm{g} / \mathrm{l}$ ). After probenecid administration (serum level $3 \mathrm{mg} / \mathrm{l}$ ) the HVA was $157 \mu \mathrm{g} / \mathrm{l}$ (normally the measurement should be at least twice as high as the control level). A pneumoencephalogram revealed marked dilatation of the lateral and third ventricles with a corpus callosal angle of $107^{\circ}$ and a lateral ventricular height of $36 \mathrm{~mm}$ (Fig. 1). Some air was seen in a few large sulci of the frontal lobes mainly in the interhemispheric area. There was no air over the frontoparietal convexities. The fourth ventricle and the aqueduct were enlarged. There was no evidence of impingement on the aqueduct by an ectatic basilar artery. Cisternography with ${ }^{111}$ Indium imaged the isotope in the ventricles at 48 hours (Fig. 2). An intrathecal salines infusion test (Katzman and Hussey, 1970) resulted $\vec{\complement}$ in a CSF pressure of $280 \mathrm{mmH}_{2} \mathrm{O}$ ai 25 minutes stabilising later at $250 \mathrm{mmH}_{2} \mathrm{O}$.

The patient underwent a right ventriculopleuratơ shunt in December 1974. Within two weeks after theoperation there was a dramatic improvement in hiș

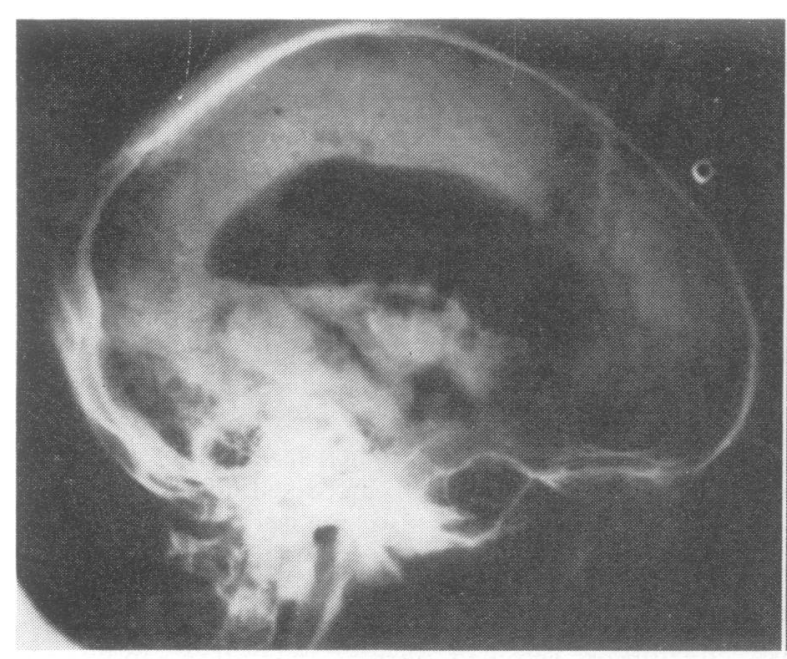

(1a)

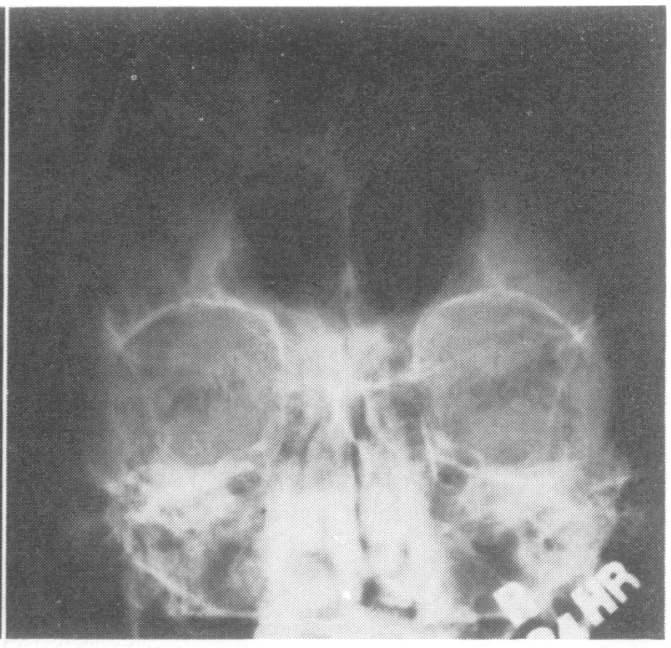

(1b)

Fig. 1 Pneumoencephalogram taken in an erect position(a) showing marked dilatation of the lateral ventricle and no air over the convexities. Corpus callosal angle is $107^{\circ}$ in a brow-up anteroposterior pneumoencephalogram (b). 


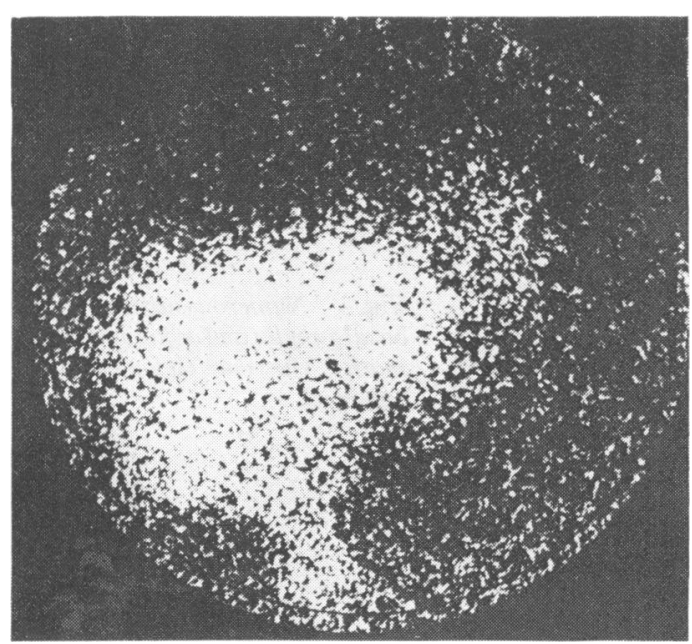

Fig. 2 Right lateral view of the ${ }^{111}$ Indium cisternogram at 48 hours showing retention of the isotope within the enlarged ventricular system.

gait with disappearance of the urinary incontinence. Repeated psychometric testing in January 1975 revealed an improvement of the verbal IQ to 126 and the performance IQ to 92 . There was an increase of the scores in digit symbol, block design, and object assembly. The Mattis Dementia Rating Score was 136 , and the verbal learning showed improvement. However, he was readmitted at the end of June 1975 because of deterioration in his gait and recurrence of urinary incontinence. The shunt appeared to be functioning properly. He was dull and responded to questions slowly with many silent periods. He perseverated and had defective comprehension. Although it was not possible to perform complete psychological testing, his IQ had fallen to the range of mentally incompetent and he seemed to have deteriorated intellectually by at least two standard deviations compared with the results obtained in January. He developed pulmonary embolism and died in August 1975.

\section{NECROPSY FINDINGS}

Postmortem examination revealed a large thromboembolus occluding the main pulmonary trunk. The heart weighed $450 \mathrm{~g}$ and the left ventricle was hypertrophic. The abdominal aorta showed an atherosclerotic saccular aneurysm. Moderate arteriolar nephrosclerosis was also present.

The brain weighed $1350 \mathrm{~g}$. The ventriculopleural shunt was in place and patent. Very thin rustcoloured subdural membranes representing resolved, old subdural haematoma were seen bilaterally. The superior sagittal sinus was patent. There was no evidence of meningeal thickening or incisural block. The arachnoid granulations displayed no fibrosis, hyperplasia of meningothelial cells, or inflammatory cell infiltration. No signs of increased intracranial pressure were evident. All the major cerebral blood vessels revealed moderate to severe atherosclerosis, but none of them was occluded. There was mild ectasia of the vertebrobasilar system associated with severe atherosclerotic changes. The lateral ventricles showed moderate symmetrical dilatation. The third ventricle was also moderately enlarged. Multiple irregular cavitary lesions (lacunes) were noted in the basal ganglia and adjoining white matter (Fig. 3). Main lesions were in the putamen and the body of the caudate nucleus on both sides and measured up to $0.8 \times 0.5 \mathrm{~cm}$. Other lacunes measuring up to 0.3 $\mathrm{cm}$ ware located in the thalamus, periventricular white matter, and basis pontis. Microscopically some of the lacunes had gliotic trabeculae and contained few foamy macrophages, while others were crowded with these cells. Many of the small intraparenchymal arteries showed concentric hypertrophy of the intima and media and marked hyalinosis with occasional fibrinoid necrosis (Fig. 4). A mediumsized artery in the thalamus was seen to be occluded by an organising thrombus (Fig. 5). Amyloid angiopathy was not evident. The cerebral cortex was unremarkable. There was no evidence of Alzheimer's or Parkinson's disease.

\section{Discussion}

The present case fulfilled the currently accepted clinical and laboratory criteria for the diagnosis of normal pressure hydrocephalus and the patient showed a marked improvement after institution of the ventriculopleural shunt. Necropsy revealed a severe hypertensive and arteriosclerotic vasculopathy associated with numerous lacunar infarcts of various chronological ages, mostly in the basal ganglia, thalami, and periventricular white matter. Leptomeningeal fibrosis and obliteration of arachnoid villi, which have been described pathologically in association with some cases of normal pressure hydrocephalus (Heinz et al., 1970; DeLand et al., 1972; Sypert et al., 1973; Lorenzo et al., 1974; Vessal et al., 1974), were absent. There was no evidence of Alzheimer's disease. There was mild ectasia of the basilar artery, but this did not impinge on the aqueduct. The subdural membranes were also considered but later ruled out as possible aetiological factor, because there was no radiological evidence of their presence before shunting and at the time of operation the neurosurgeon did not observe any abnormal membrane. Therefore, we reasonably felt that the subdural haematoma developed later, 


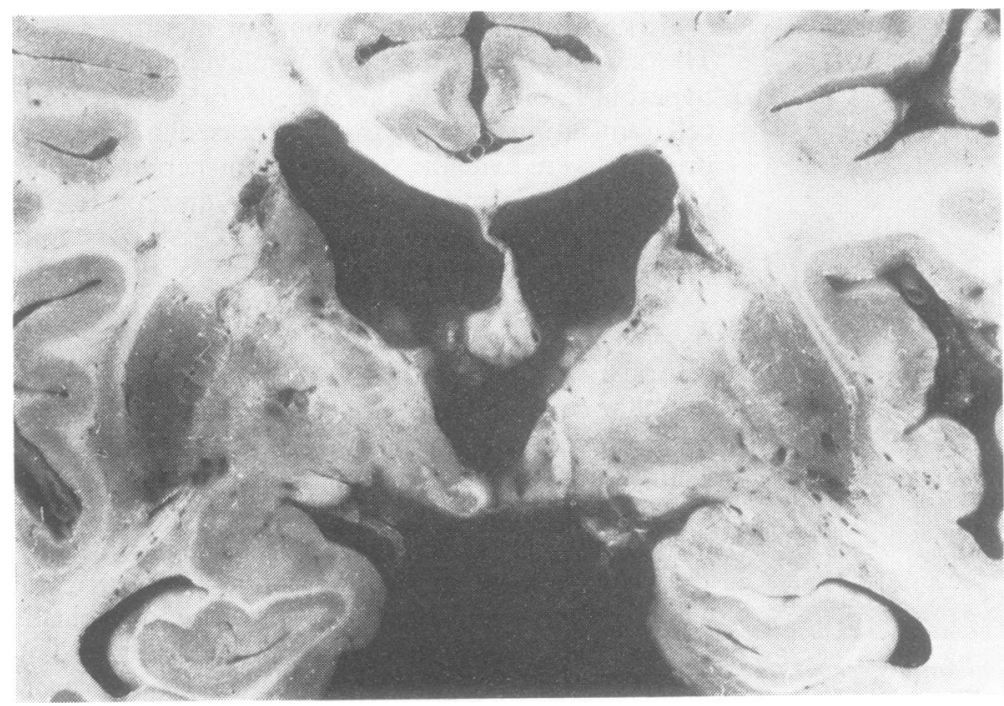

Fig. 3 Numerous lacunes in the basal ganglia and adjoining white matter. The ventricles are enlarged.

possibly as a complication of the decompression and did not participate in precipitating the syndrome of normal pressure hydrocephalus.

It is of interest that review of the literature reveals a very high incidence of hypertensive and/or arteriosclerotic cerebrovascular disease in patients with idiopathic normal pressure hydrocephalus (DeLand et al., 1972; Crowell et al., 1973; Earnest et al., 1974; Lorenzo et al., 1974; Stein and Langfitt, 1974; Vessal et al., 1974). In a series reported by Vessal et al. (1974), four out of their five patients had definite cerebrovascular changes as well as arachnoid fibrosis and some did display lacunar lesions. Singounas et al. (1976) also reported patients with normal pressure hydrocephalus who angiographically displayed arteriosclerotic changes and responded favourably to shunt procedures. Earnest and associates (1974) described two necropsy cases with hypertensive vascular disease and an advanced lacunar state, but normal leptomeninges and arachnoid villi. These findings were similar to those seen in the present case. Earnest et al. (1974) proposed that the ventricular enlargement in their patients was due to the effect of increased CSF pulse pressure on a ventricle whose tensile strength had been altered by loss of periventricular tissue. The resultant enlargement was said to compromise CSF absorption by compressing the brain tissue against the calvarium. However, several recent studies (Stein and Langfitt, 1974; Shenkin et al., 1975; Belloni et al., 1976; Jacobs et al., 1976) have demonstrated that the severity of the clinical manifestation is not in direct proportion to the degree of hydrocephalus and that there is no consistent relationship between clinical amelioration and reduction of ventricular size after shunting; this suggests that some factors other than the ventricular size per se may be of significance in the development of the symptoms and postoperative improvement.

A rise in the 5-HIAA level in the CSF of hydrocephalic children has been reported by Andersson and Roos (1969) and others (Hansson, 1970; Morio et al., 1973). In the present case a rise was noted in the concentration of HVA as well as of 5-HIAA. The increase of HVA in the CSF is not in accordance with the result reported by Maira et al. (1975), who found a low HVA content in a series of patients with suspected normal pressure hydrocephalus and evidence of reduced CSF absorption. Since acid monoamine metabolites in the CSF are cleared by an active transport mechanism across the capillaries (Wolfson et al., 1974), the alterations in the small blood vessels seen in our patient might have interfered with the normal clearance mechanism resulting in increased CSF levels of 5-HIAA and HVA. The improvement of the neurological manifestations after shunting might be related to the disposal of these metabolites from the CSF. Of interest is a recent report that documented amyloid angiopathy of meningeal and cortical arterioles in two patients with normal pressure hydrocephalus (Torack, 1975). Cerebral blood vessels under certain conditions are thought to provide a minor route for the removal of CSF (Bowsher, 1960; Milhorat, 1972; Katzman and Pappius, 1973). The development of hydrocephalus might be attributed to an obstruction to CSF absorption at the level of the small blood vessels.

It has also been found that cerebral blood flow is reduced in cases of normal pressure hydrocephalus and that the cerebral blood flow increases after 


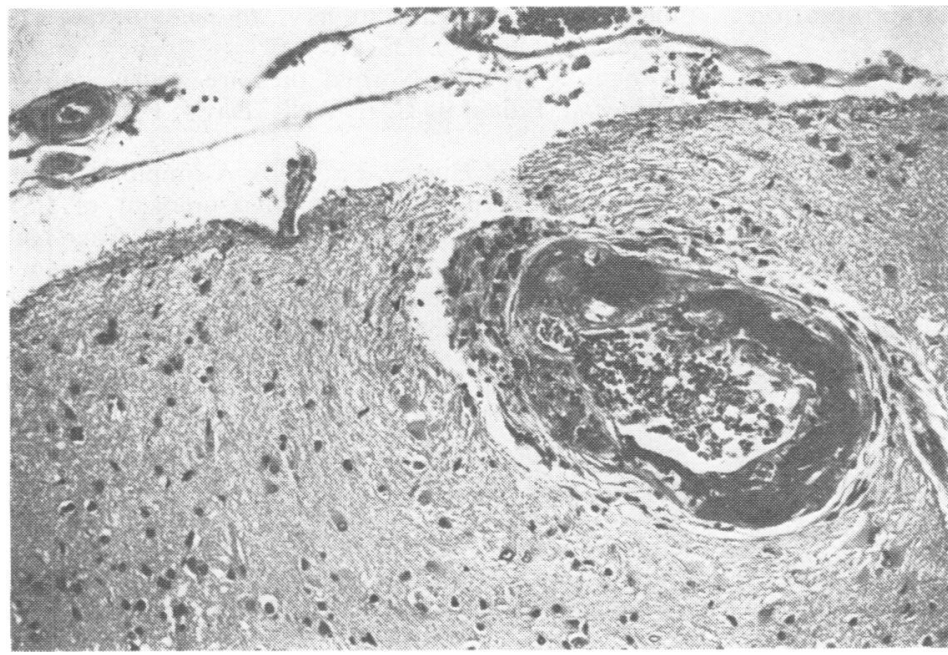

Fig. 4 Acorticalblood vessel in the frontal lobe showing fibrinoid necrosis. Note also absence of meningeal fibrosis. $H$ and $E, \times 110$.

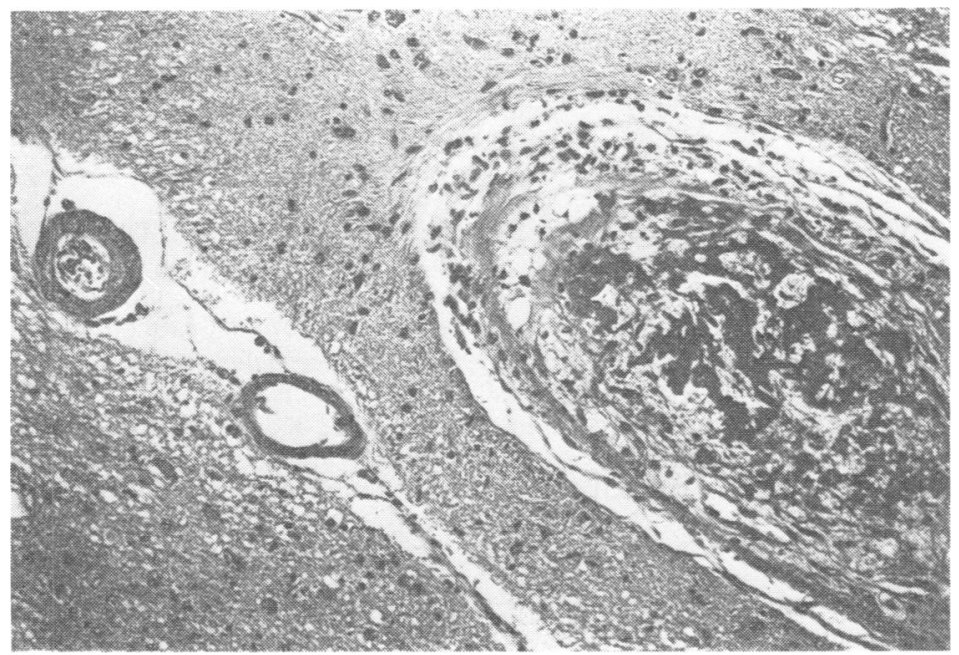

Fig. 5 A section from the thalamus showing an artery occluded by an organising thrombus. Smaller vessels show hyalinosis. $H$ and $E, \times 110$.

shunting (Greitz et al., 1969; Salmon and Timperman, 1971). This increase is usually associated with postoperative improvement in neurological symptoms. Mathew and colleagues (1975) considered that the increase in cerebral blood flow indicated an imparred autoregulation of cerebral blood flow. Dysautoregulation of cerebral blood flow, on the other hand, has been clearly demonstrated in ischaemic cerebrovascular disease especially when the lesions are acute or subacute and located deep in the brain (Meyer et al., 1973). In our case, there were multiple new and old ischaemic lesions involving the deep structures of the brain. Thus, it is possible that autoregulation had been impaired in the present case and the cerebral blood flow increased as perfusion pressure to the brain was augmented when CSF pressure was lowered by a shunt. In addition, it is conceivable that the increase in cerebral blood flow after shunting further accelerated the removal of CSF and metabolic products from the brain.

The observation of advanced hypertensive and arteriosclerotic disease in the present case with normal pressure hydrocephalus suggests that cerebral vasculopathy can be another cause of this syndrome. Further careful analysis of the cerebral blood vessels in patients with this syndrome is needed in the future. 
We wish to thank Dr Paula Fuld for interpretation of the psychometric data.

\section{References}

Adams, R. D., Fisher, C. M., Hakim, S., Ojemann, R. G., and Sweet, W. H. (1965). Symptomatic occult hydrocephalus with 'normal' cerebrospinal-fluid pressure. A treatable syndrome. New England Journal of Medicine, 273, 117-126.

Andersson, H., and Roos, B.-E. (1969). 5-hydroxyindoleacetic acid in cerebrospinal fluid of hydrocephalic children. Acta Paediatrica Scandinavica, 58, 601-608.

Belloni, G., di Rocco, C., Focacci, C., Galli, G., Maira, G., and Rossi, G. F. (1976). Surgical indications in normotensive hydrocephalus. A retrospective analysis of the relations of some diagnostic findings to the results of surgical treatment. Acta Neurochirurgica, 33, $1-21$.

Benson, D. F., LeMay, M., Patten, D. H., and Rubens, A. B. (1970). Diagnosis of normal-pressure hydrocephalus. New England Journal of Medicine, 283, 609-615.

Bowsher, D. (1960). Cerebrospinal Fluid Dynamics in Health and Disease. Thomas: Springfield, Ill.

Coblentz, J. M., Mattis, S., Zingesser, L. H., Kasoff, S. S., Wiśniewski, H. M., and Katzman, R. (1973). Presenile dementia. Clinical aspects and evaluation of cerebrospinal fluid dynamics. Archives of Neurology (Chic.), 29, 299-308.

Crowell, R. M., Tew, J. M., Jr, and Mark, V. H. (1973). Aggressive dementia associated with normal pressure hydrocephalus. Report of two unusual cases. Neurology (Minneap.), 23, 461-464.

DeLand, F. H., James, A. E., Jr, Ladd, D. J., and Konigsmark, B. W. (1972). Normal pressure hydrocephalus: A histologic study. American Journal of Clinical Pathology, 58, 58-63.

Earnest, M. P., Fahn, S., Karp, J. H., and Rowland, L. P. (1974). Normal pressure hydrocephalus and hypertensive cerebrovascular disease. Archives of Neurology (Chic.), 31, 262-266.

Greitz, T. V. B., Grepe, A. O. L., Kalmér, M. S. F., and Lopez, J. (1969). Pre- and postoperative evaluation of cerebral blood flow in low-pressure hydrocephalus. Journal of Neurosurgery, 31, 644-651.

Hakim, S., and Adams, R. D. (1965). The special clinical problem of symptomatic hydrocephalus with normal cerebrospinal fluid pressure. Observations on cerebrospinal fluid hydrodynamics. Journal of the Neurological Sciences, 2, 307-327.

Hansson, O. (1970). Hydrocephalus and 5-hydroxyindoleacetic acid in the CSF. Developmental Medicine and Child Neurology, 12, 103-104.

Heinz, E. R., Davis, D. O., and Karp, H. R. (1970). Abnormal isotope cisternography in symptomatic occult hydrocephalus. A correlative isotopic-neuroradiological study in 130 subjects. Radiology, 95, 109-120.

Jacobs, L., Conti, D., Kinkel, W. R., and Manning, E. J. (1976). 'Normal-pressure' hydrocephalus. Relationship of clinical and radiographic findings to improve- ment following shunt surgery. Journal of American Medical Association, 235, 510-512.

Katzman, R. (1977). Normal pressure hydrocephalus. Dementia. Edited by C. E. Wells. Davis: Philadelphia. (In press.)

Katzman, R., and Hussey, F. (1970). A simple constantinfusion manometric test for measurement of CSF absorption. I. Rationale and method. Neurology (Minneap.), 20, 534-544.

Katzman, R., and Pappius, H. M. (1973). Brain Electrolytes and Fluid Metabolism. Williams and Wilkins: Baltimore.

Lorenzo, A. V., Bresnan, M. J., and Barlow, C. F. (1974). Cerebrospinal fluid absorption deficit in normal pressure hydrocephalus. Archives of Neurology (Chic.), 30, 387-393.

Maira, G., Bareggi, S. R., di Rocco, C., Calderini, G., and Morselli, P. L. (1975). Monoamine acid metabolites and cerebrospinal fluid dynamics in normal pressure hydrocephalus: preliminary results. Journal of Neurology, Neurosurgery, and Psychiatry, 38, 123-128.

Mathew, N. T., Meyer, J. S., Hartmann, A., and Ott, E. O. (1975). Abnormal cerebrospinal fluid-blood flow dynamics. Implications in diagnosis, treatment, and prognosis in normal pressure hydrocephalus. Archives of Neurologv (Chic.), 32, 657-664.

Messert, B., and Wannamaker, B. B. (1974). Reappraisal of the adult occult hydrocephalus syndrome. Neurology (Minneap.), 24, 224-231.

Meyer, J. S., Shimazu, K., Fukuuchi, Y., Ohuchi, T., Okamoto, S., Koto, A., and Ericsson, A. D. (1973). Impaired neurogenic cerebrovascular control and dysautoregulation after stroke. Stroke, 4, 169-186.

Milhorat, T. H. (1972). Hydrocephalus and the Cerebrospinal Fluid. Williams and Wilkins: Baltimore.

Mori, K., Fujita, Y., Waga, S., Kondo, Y., and Handa, H. (1973). Hydrocephalus and amine metabolites in the CSF (A pilot study). Brain and Nerve, 25, 1005-1010.

Ojemann, R. G., Fisher, C. M., Adams, R. D., Sweet, W. H., and New, P. F. J. (1969). Further experience with the syndrome of 'normal' pressure hydrocephalus. Journal of Neurosurgery, 31, 279-294.

Salmon, J. H., and Timperman, A. L. (1971). Effect of intracranial hypotension on cerebral blood flow. Journal of Neurology, Neurosurgery, and Psychiatry, 34, 687-692.

Shenkin, H. A., Greenberg, J. O., and Grossman, C. B. (1975). Ventricular size after shunting for idiopathic normal pressure hydrocephalus. Journal of Neurology, Neurosurgery, and Psychiatry, 38, 833-837.

Singounas, E. G., Krasanakis, C., and Karvounis, P. C. (1976). Observations on the pathogenesis of low pressure hydrocephalus. Analysis of 25 cases. Neurochirurgia, 19, 22-25.

Sohn, R. S., Siegel, B. A., Gado, M., and Torack, R. M. (1973). Alzheimer's disease with abnormal cerebrospinal fluid flow. Neurology (Minneap.), 23, 1058-1065.

Stein, S. C., and Langfitt, T. W. (1974). Normal-pressure hydrocephalus. Predicting the results of cerebrospinal fluid shunting. Journal of Neurosurgery, 41, 463-470. 
Sypert, G. W., Leffman, H., and Ojemann, G. A. (1973). Occult normal pressure hydrocephalus manifested by parkinsonism-dementia complex. Neurology (Minneap.), 23, 234-238.

Torack, R. M. (1975). Congophilic angiopathy complicated by surgery and massive hemorrhage. A light and electron microscopic study. American Journal of Pathology, 81, 349-366.

Vessal, K., Sperber, E. E., and James, A. E., Jr, (1974). Chronic communicating hydrocephalus with normal
CSF pressures: A cisternographic-pathologic correlation. Annales de Radiologie (Paris), 17, 785-793.

Wolfson, L. I., Katzman, R., and Escriva, A. (1974). Clearance of amine metabolites from the cerebrospinal fluid: The brain as a 'sink'. Neurology (Minneap.), 24, 772-779.

Wood, J. H., Bartlet, D., James, A. E., Jr, and Udvarhelyi, G. B. (1974). Normal-pressure hydrocephalus: Diagnosis and patient selection for shunt surgery. Neurology (Minneap.), 24, 517-526. 